\title{
DOJO KYOKUSHIN KARATE KALIMANTAN SELATAN
}

\author{
Adji Purnama Sandi \\ Program Studi Teknik Arsitektur Fakultas Teknik Universitas Lambung Mangkurat \\ adjipurnamasandi@gmail.com \\ Gusti Novi Sarbini \\ Program Studi Teknik Arsitektur Fakultas Teknik Universitas Lambung Mangkurat \\ gustinovi@ulm.ac.id
}

\begin{abstract}
ABSTRAK
Kyokushin karate di Kalimantan Selatan merupakan salah satu beladiri yang masih menerapkan sistem tarung full contact. Para praktisi kyokushin karate di Kalimantan Selatan tidak mempunyai tempat latihan sendiri, dan terpaksa harus menyewa tempat. Dojo kyokushin karate kalimantan selatan bertujuan menciptakan tempat latihan tersendiri khusus untuk para praktisi kyokushin karate yang memiliki nilai-nilai dari filosofi kyokushin itu sendiri, agar mengerti bahwa seni bertarung hanya merupakan alat untuk menyempurnakan jiwa dan raga, serta bisa menjadi landasan yang kuat untuk membangun manusia seutuhnya. Filosofi kyokushin sebagai konsep akan dipadukan dengan metode linguistik sebagai tujuan penyelesaian permasalahan pada perancangan dojo ini.
\end{abstract}

Kata kunci: Kyokushin karate, filosofi kyokushin, linguistik, dojo.

\section{ABSTRACT}

Kyokushin karate in South Kalimantan is one of the martial arts that still applies a full contact fighting system. The kyokushin karate practitioners in South Kalimantan do not have their own practice sites, and are forced to rent a place to practice. The kyokushin karate dojo in South Kalimantan aims to create a special training ground for practitioners of kyokushin karate who have values from the kyokushin philosophy itself, so that they understand that the art of fighting is only a tool to perfect the body and soul, and can be a strong foundation for human development completely. The philosophy of Kyokushin as a concept will be combined with linguistic methods as the goal of solving problems in the design of this dojo.

Keywords: Kyokushin karate, kyokushin philosophy, linguistics, dojo.

\section{PENDAHULUAN}

Kyokushin karate di Kalimantan Selatan merupakan salah satu beladiri yang menerapkan sistem tarung full contact. Dikarenakan pelatih utama pindah tugas ke Jakarta maka cabang olahraga ini menjadi vakum cukup lama. Dikarenakan tidak ada tempat latihan tetap, para praktisinya tidak tahu dimana harus melanjutkan latihan mereka, karena lisensi tempat latihan sebelumnya dipegang oleh pelatih utama, itupun tempat latihannya menyewa dan bergabung dengan tempat latihan beladiri lain, sehingga banyak sekali praktisinya yang tidak pernah latihan lagi karena ketidak jelasan tempat latihan mereka. Kyokushin karate sendiri sangat populer sampai ke luar

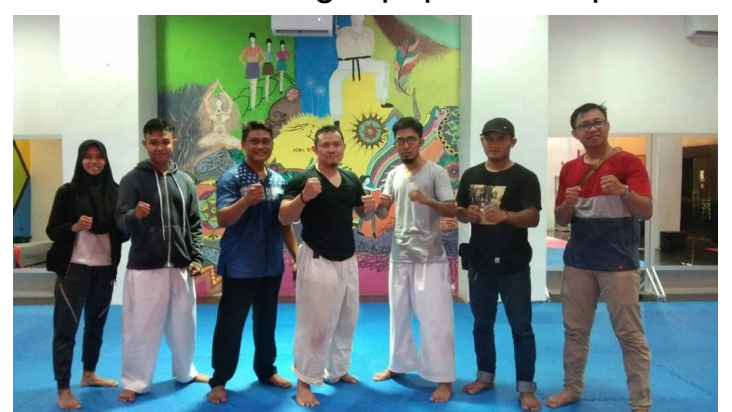


negeri sangat populer dan banyak tokoh dunia terkenal seperti Presiden Rusia Vladimir Putin, serta beberapa aktor perfilman hollywood seperti Dolph Lundgren, Hiroyuki Sanada, dan petarung legendaris UFC di kelas Welterweight yaitu Georges St-Pierre, semuanya merupakan praktisi beladiri ini. Keefektifan beladiri ini dalam perkelahian jalanan pun sudah sangat teruji. Para praktisi Kyokushin Karate Kalimantan Selatan mengharapkan adanya Dojo tempat mereka berlatih sendiri dan tidak tergabung dengan beladiri lain, jadi mereka bisa fokus dalam mengembangkan ilmu, fisik mereka dengan fasilitas-fasilitas mereka sendiri, seperti target pukul tendang, barbel, dan alat lainnya yang bisa mereka gunakan untuk melatih daya tahan tubuh mereka. Dibuatnya dojo khusus kyokushin dikarenakan para praktisinya juga ingin masyarakat tahu bahwa karate mereka berbeda dengan karate lainnya, karena mempunyai perbedaan dari tujuan karate ini diciptakan, filosofinya, cara bertarungnya, hingga cara berlatihnya pun beda, karena mereka masih menerapkan teknik beladiri tradisional yang memang bertujuan untuk digunakan dalam perkelahian sebenarnya.

Gambar 1. Praktisi kyokushinkai di Dojo Aswa Studio.

\section{PERMASALAHAN}

Berdasar latar belakang diatas, perlunya dojo kyokushin karate Kalimantan Selatan maka yang menjadi permasalahan arsitektur adalah bagaimana rancangan dojo kyokushin karate Kalimantan Selatan yang memiliki nilai filosofi dari kyokushin itu sendiri sehingga dapat memunculkan jiwa petarung pada setiap praktisinya melalui rancangan.

\section{TINJAUAN PUSTAKA}

\section{A. Pengertian Judul}

Dalam karate terdapat 3 falsafah sebagai pegangan karateka. Falsafah tersebut bertujuan agar karateka dapat menguasai diri dari rasa takut dengan menghilangkan ketidakpedulian terhadap rasa takut dengan membentuk pilar lain yaitu kejujuran, disiplin, dan kreativitas. Falsafah ini mengajarkan bagaimana mengatasi rasa takut dengan pikiran layaknya permukaan air yang tenang dan bulan (Nugraha, 2010).

Linguistik adalah pengkajian Arsitektur dalam bahasa komunikasi, bahasa terdiri dari kata-kata yang memiliki arti. Begitu pula dengan karya-karya Arsitektural yang juga merupakan kumpulan dari elemen-elemen pembentuk yang memiliki/memancarkan suatu makna/arti (Makainas, 2012).

\section{PEMBAHASAN}

\section{A. Lokasi}

Tapak Terletak di JI. Ir. P. M. Noor, dikarenakan lokasi site cocok, dan lokasinya pun ideal karena berada diatas ketinggian dengan kontur miring. Luas Tapak 2.135 m2.

Dengan Batasan Tapak:

$$
\begin{array}{ll}
\text { - Utara } & \text { : Jalan Ir. P. M. Noor. } \\
\text { - Selatan } & \text { : Bukit Patrabulu. } \\
\text { - Timur } & \text { : Lahan Kosong. } \\
\text { - Barat } & \text { : Lahan Kosong. }
\end{array}
$$

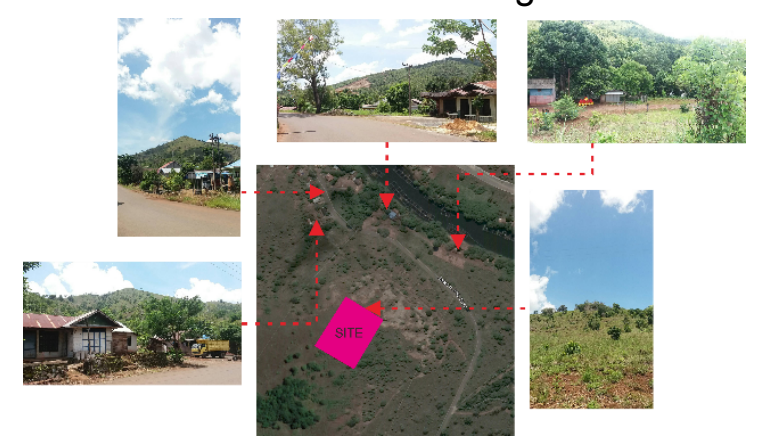

Gambar 2. Kondisi Site

\section{B. Konsep Rancangan}

1. Konsep Rancangan

Konsep programatik merupakan suatu gagasan mengenai penyelesaian masalah. Berdasarkan permasalahan dari dojo kyokushin karate kalimantan selatan yaitu bagaimana rancangan dojo kyokushin karate Kalimantan Selatan yang memiliki nilai filosofis dari kyokushin itu sendiri sehingga 
dapat memunculkan jiwa petarung pada setiap praktisinya melalui rancangan ? maka dari itu filosofi kyokushin itu sendiri dijadikan sebagai konsep utama ke dalam rancangan agar dapat mewadahi berbagai kegiatan para praktisi kyokushin karate.

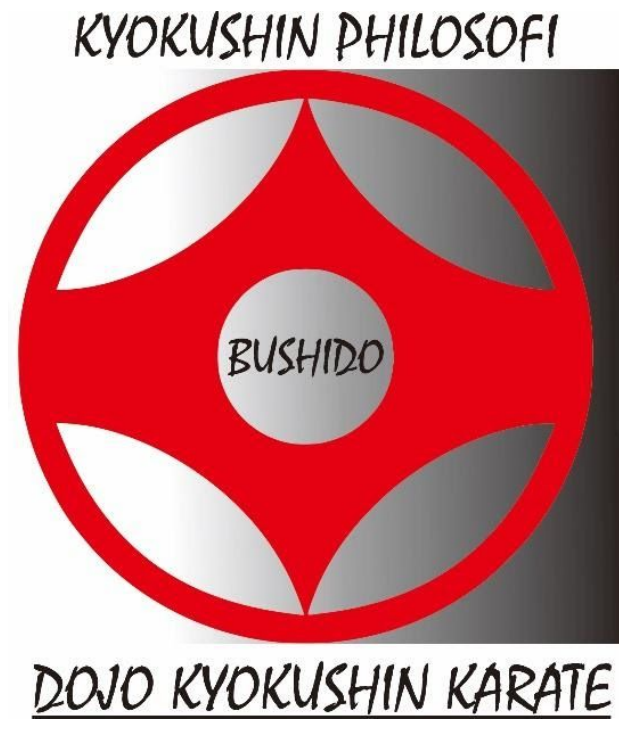

Gambar 3. Konsep Programatik Filosofi Kyokushin .

\section{Konsep Perancangan}

Konsep perancangan ini menggunakan metode linguistik yang diterapkan pada perancangan Dojo Kyokushin Karate Kalimantan Selatan ini diharapkan memudahkan para praktisi, maupun calon praktisi mengerti tentang maksud sebenarnya dari filosofi kyokushin itu sendiri. Melalui metode linguistik ini dapat menceritakan perjuangan dan kerja keras terbentuknya beladiri ini yang mendapatkan banyak halangan dan tantangan, sehingga dari bangunan ini para

penghuninya dapat merasakan dan paham arti sebenarnya dari perjuangan dari seorang petarung sejati dari berbagai sisi bangunan dan lingkungan serta paham bahwa seni bertarung hanya merupakan alat untuk menyempurnakan jiwa dan raga, serta bisa menjadi landasan yang kuat untuk membangun manusia seutuhnya. Dengan memasukan metode linguistik, bangunan dojo diharapkan dapat tergambarkan lugas, kuat, tegak dan meninggi untuk menunjukan bahwa dengan didirikannya dojo ini dapat menjadikan praktisi tersebut manusia seutuhnya baik jiwa maupun raga.

\section{Konsep Bangunan}

Konsep yang digunakan pada perancangan didasarkan pada kata kunci dari kyokushin itu sendiri yaitu 1 pukulan, sehingga bangunan terkesan keras, lugas, dan sederhana dengan tidak menambahkan berbagai macam ornamen.

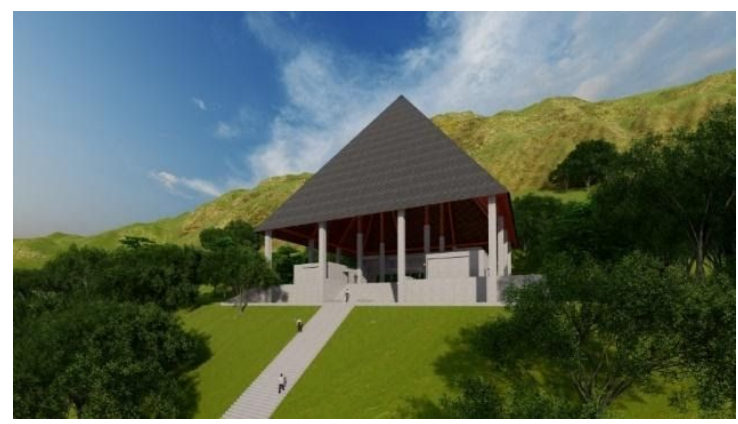

Gambar 4. Konsep Bangunan.

\section{Konsep Ruangan}

Konsep ruangan yang dipakai menggunakan konsep dari filosofi kyokushin itu sendiri dengan membuat ruangan menjadi semi outdoor pada area tempat berlatih. Sehingga udara, suhu dingin panas, hujan, bahkan badai pun menjadikan rasa tersendiri ketika berlatih karena hal tersebut tidak menghentikan para praktisi dalam mendalami arti dari beladiri sebenarnya, sehingga dapat membuat tubuh para praktisi

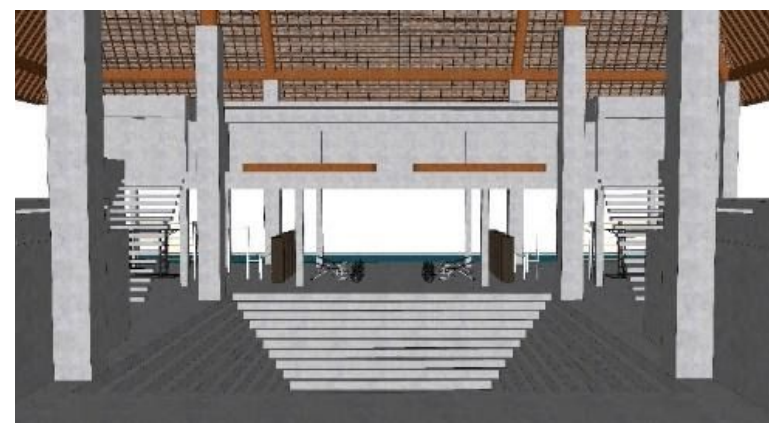


terbiasa di berbagai kondisi lingkungan dan cuaca yang buruk.

Gambar 5. Kondisi Site.
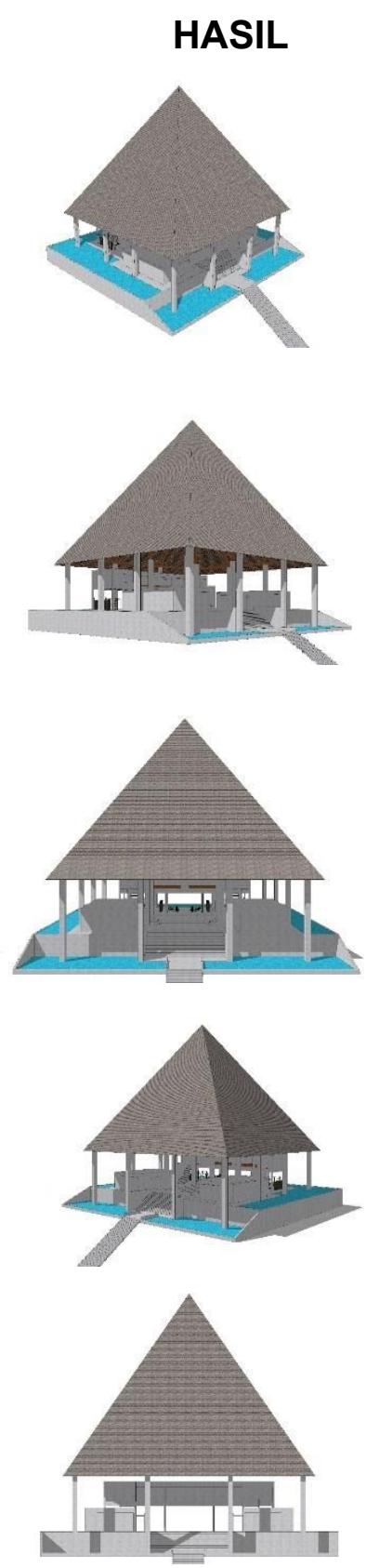

Gambar 6. Perspektif dan Tampak Rancangan.

\section{KESIMPULAN}

Para praktisi Kyokushin Karate Kalimantan Selatan mengharapkan adanya Dojo tempat mereka berlatih sendiri dan tidak tergabung dengan beladiri lain, jadi mereka bisa fokus dalam mengembangkan ilmu, fisik mereka dengan fasilitas-fasilitas mereka sendiri, seperti target pukul tendang, barbel, dan alat lainnya yang bisa mereka gunakan untuk melatih daya tahan tubuh mereka.

Fokus masalah yang akan diselesaikan pada Dojo kyokushin karate yaitu bagaimana rancangan dojo kyokushin karate Kalimantan Selatan yang memiliki nilai filosofi dari kyokushin itu sendiri sehingga dapat memunculkan jiwa petarung pada setiap praktisinya melalui rancangan.

Digunakannya filosofi kyokushin pada konsep perancangan ini memudahkan para praktisinya untuk memahami arti beladiri atau seni bertarung sebenarnya, dan metode yang dipilih dibuat agar para praktisinya mengerti bahwa seni bertarung hanya merupakan alat untuk menyempurnakan jiwa dan raga, serta bisa menjadi landasan yang kuat untuk membangun manusia seutuhnya.

\section{DAFTAR PUSTAKA}

Nugraha. 2010. Tenaga KI Karate. Retrieved from Karate Harmony.

Makainas, Indradjaja., dan Astrid Rawung. 2012. Konsep Linguistik Dalam Rancangan Arsitektur. UNSRAT : Manado. 